\title{
Improvement of metal adsorption onto chitosan/Sargassum sp. composite sorbent by an innovative ion-imprint technology
}

\author{
Huijuan Liu ${ }^{a, *}$, Fan Yang ${ }^{a, c}$, Yuming Zheng ${ }^{b}$, Jin Kang ${ }^{a, c}$, Jiuhui Qu ${ }^{a}$, J. Paul Chen ${ }^{b, * *}$ \\ a State Key Laboratory of Environmental Aquatic Chemistry, Research Center for Eco-Environmental Sciences, Chinese Academy of Sciences, \\ 18, Shuangqing Road, Beijing 100085, China \\ ${ }^{\mathrm{b}}$ Division of Environmental science and Engineering, National University of Singapore, 10 Kent Ridge Crescent, Republic of Singapore 119260 \\ ${ }^{\mathrm{c}}$ Graduate School, Chinese Academy of Sciences, Beijing 100039, China
}

\section{A R T I C L E I N F O}

Article history:

Received 16 March 2010

Received in revised form

15 July 2010

Accepted 10 August 2010

Available online 17 August 2010

Keywords:

Biosorption

Copper removal

Granulation

Ion-imprinted chitosan

Sargassum sp.

\begin{abstract}
A B S T R A C T
Technology for immobilization of biomass has attracted a great interest due to the high sorption capacity of biomass for sequestration of toxic metals from industrial effluents. However, the currently practiced immobilization methods normally reduce the metal sorption capacities. In this study, an innovative ion-imprint technology was developed to overcome the drawback. Copper ion was first imprinted onto the functional groups of chitosan that formed a pellet-typed sorbent through the granulation with Sargassum sp.; the imprinted copper ion was chemically detached from the sorbent, leading to the formation of a novel copper ion-imprinted chitosan/Sargassum sp. (CICS) composite adsorbent. The copper sorption on CICS was found to be highly $\mathrm{pH}$-dependent and the maximum uptake capacity was achieved at $\mathrm{pH}$ 4.7-5.5. The adsorption isotherm study showed the maximum sorption capacity of CICS of $1.08 \mathrm{mmol} / \mathrm{g}$, much higher than the non-imprinted chitosan/Sargassum sp. sorbent (NICS) $(0.49 \mathrm{mmol} / \mathrm{g})$. The used sorbent was reusable after being regenerated through desorption. The FTIR and XPS studies revealed that the greater sorption of heavy metal was attributed to the large number of primary amine groups available on the surfaces of the ion-imprinted chitosan and the abundant carboxyl groups on Sargassum sp.. Finally, an intraparticle surface diffusion controlled model well described the sorption history of the sorbents.
\end{abstract}

(c) 2010 Elsevier Ltd. All rights reserved.

\section{Introduction}

Biosorption has been considered as a promising technology for the removal of low-level toxic metals from industrial effluents and natural waters (Volesky, 2007; Mehta and Gaur, 2005; Wang and Chen, 2009). Marine algae have received greater attention because of their high metal biosorption capacity, low cost, and renewable nature. They can effectively remove heavy metal ions with concentrations ranging from few ppm to several hundreds ppm. The maximum metal biosorption capacity ranging from 0.1 to $1.5 \mathrm{mmol} / \mathrm{g}$ biosorbent has been reported (Davis et al., 2003; Chen and Yang, $2005,2006)$. However, biosorbents often have small size, weak mechanical strength and low density. Leaching of such

\footnotetext{
* Corresponding author. Tel./fax: +86 1062849160 .

** Corresponding author. Fax: +65 68725483.

E-mail addresses: hjliu@rcees.ac.cn (H. Liu), jchen.enve97@gtalumni.org (J.P. Chen). 0043-1354/\$ - see front matter @ 2010 Elsevier Ltd. All rights reserved. doi:10.1016/j.watres.2010.08.017
} 
organics as carbohydrates and protein may be serious when some of biosorbents (e.g. raw seaweed) are used. These drawbacks have hindered the applications for treatment of waste metallic streams from various sources.

In recent years, various efforts have been focused on the immobilization of alga biomass, which is a potential way to overcome the disadvantages. Such supporting materials as alginate (Bayramoğlu and Yakup Arıca, 2009; Mata et al., 2009), silica gel (Rangsayatorn et al., 2004), polyacrylamide and polyurethanes (Mehta and Gaur, 2005) were used for the biomass immobilization. However, metal uptake efficiency of immobilized cells is reportedly often much lower than that of raw biomass. The functional groups on biomass for metal binding may become less available due to the immobilization and thus the sorption becomes normally less. For example, the cadmium sorption capacity drops from $98 \mathrm{mg}-\mathrm{Cd} / \mathrm{g}$ for the Spirulina platensis to 71 and $37 \mathrm{mg}-\mathrm{Cd} / \mathrm{g}$ for the alginate and silica immobilized species, respectively (Rangsayatorn et al., 2004). Mata et al. (2009) reported that the sorption capacity of alginate immobilized Fucus vesiculosus for copper was reduced nearly $60 \%$ due to immobilization. Synthetic polymers, such as polyacrylamide and polyurethanes, may be used for immobilization of biomass; the high cost and toxicity restrict their applications (Mehta and Gaur, 2005).

Chitosan produced by partial deacetylation of chitin is the second most abundant biopolymer next to cellulose in nature. In addition to the high adsorption capacity for various heavy metals (Bassi et al., 2000; Guibal, 2004), chitosan can easily form hydrogel (Zhao et al., 2007). Thus, chitosan may be a good carrier for immobilization of biomass. However, the chitosanbased hydrogel are often poorly resistant to acid and has weak mechanical strength. In order to overcome the weaknesses, a cross-linking approach has commonly been used; the disadvantage is that the sorption capacity becomes reduced after cross-linking (Hsien and Rorrer, 1997; Ruiz et al., 2000).

In this study, an innovative ion-imprint technology illustrated in Fig. 1 was developed and used for the immobilization of alga biomass with the objectives of achievement of the higher sorption capacity of biomass and prevention of leaching of organics. Metal ion is used as an imprint ion to first "occupy" some of the functional groups (adsorption sites) in immobilization agent that can be used for metal adsorption shown as Step (1). The immobilization agent and biomass are solidified into a pellet shown as Step (2). Finally, elution agents (e.g., EDTA and $\mathrm{NaOH}$ ) are used to strip the "pre-occupied" metal ions from the functional groups (elution of imprinted metal ions) so that they become available for metal sorption illustrated as Step (3).

The chitosan was selected as an immobilization agent for Sargassum sp., which has higher metal uptake capacity and is abundant in many parts of the world (Chen and Yang, 2005, 2006; Mehta and Gaur, 2005). More importantly, it originates from natural living organisms and is not toxicity to human beings. A copper imprinted chitosan/Sargassum (CICS) composite sorbent was prepared according to the abovementioned ion-imprint technology. The adsorption properties such as $\mathrm{pH}$ effect and adsorption isotherm were studied. The surface characteristics of sorbent and sorption mechanisms were elucidated through Fourier transform infrared spectroscopy (FTIR) and X-ray photoelectron spectroscopy (XPS) analysis.

\section{Materials and methods}

\subsection{Materials}

The raw biomass of Sargassum sp. was collected from the coast of Singapore. The biomass was first washed with deionized (DI) water, and then dried overnight in an oven at $60^{\circ} \mathrm{C}$. The dried seaweed was ground to fine particles with size below $150 \mu \mathrm{m}$. Chitosan (90\% deacetylation), acetic acid and copper sulfate were purchased from Sinopharm Chemical Reagent Company (China). Sodium pyrophosphate was provided by

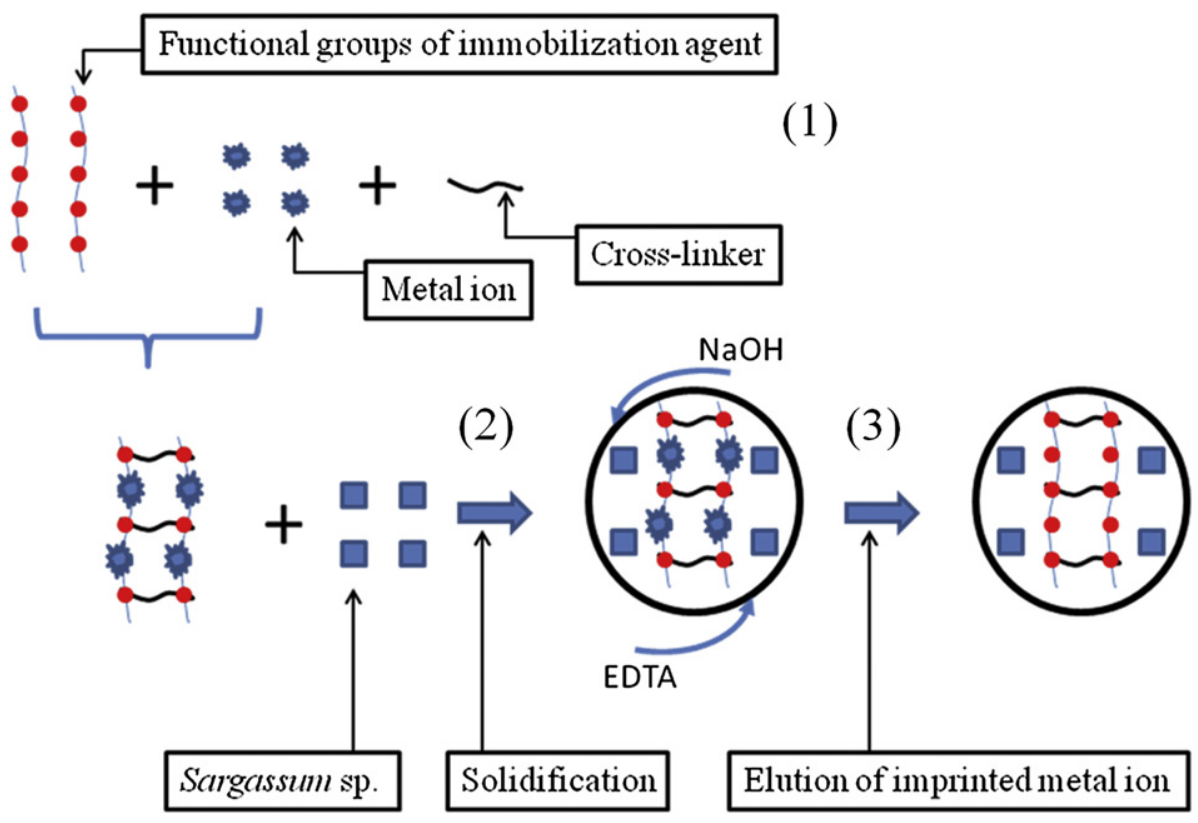

Fig. 1 - Demonstration of fabrication of metal imprinted composite sorbents. 
Tianjin Fuchen Chemical Reagent Company (China). Potassium oxalate and sodium nitrate were obtained from Beijing Chemical Reagent Company (China). All the chemicals were of analytical grade.

\subsection{Sorbent preparation}

$0.01 \mathrm{~g} \mathrm{CuSO}_{4} \cdot 5 \mathrm{H}_{2} \mathrm{O}$ was dissolved into $30 \mathrm{~mL}$ acetic acid $(0.5 \mathrm{~mol} / \mathrm{L})$, followed by an addition of $0.5 \mathrm{~g}$ chitosan. Ultrasonication was used to promote the dissolution of chitosan. $0.05 \mathrm{~mL}$ epichlorohydrin was added to the mixture for $24 \mathrm{~h}$ at room temperature for cross-linkage of chitosan. $1.5 \mathrm{~g}$ Sargassum sp. was then added into the cross-linked mixture and stirred for $1 \mathrm{~h}$. The mixture was dropwise injected into a sodium pyrophosphate and potassium oxalate solution to form small pellets. The pellets were aged for $30 \mathrm{~min}$ in the solution to enhance their mechanical stabilities. They were collected by filtration, and the residual sodium pyrophosphate and potassium oxalate solution were removed with a DI water.

Finally, the pellets were eluded by $6.8 \mathrm{mmol} / \mathrm{L}$ EDTA for $24 \mathrm{~h}$ and then with $0.03 \mathrm{~mol} / \mathrm{L} \mathrm{NaOH}$ for $2 \mathrm{~h}$ in a shaking bath to strip the chelated $\mathrm{Cu}$ (II) on the chitosan. The CICS composite sorbent was rinsed by DI water and dried at $50{ }^{\circ} \mathrm{C}$ in an oven.

In order to find out the effect of imprinted copper ion on the improvement in metal sorption, two other sorbents were prepared. A non-imprinted chitosan/Sargassum sp. (NICS) sorbent was prepared according to the above approach with an exception that the copper ion was not added. The cross-linked chitosan (CLC) was prepared without copper and Sargassum sp.

The specific surface areas of sorbents were measured by nitrogen adsorption/desorption isotherm method at liquid nitrogen temperature using the Accelerated Surface Area and Porosimetry (ASAP 2000, U.S.A., Micromeritics Co.). The Brunauer-Emmett-Teller (BET) model was applied to calculate the apparent surface area.

\subsection{Batch biosorption experiments}

All experiments were conducted at $25 \pm 0.1^{\circ} \mathrm{C}$. For kinetics experimental study, 2 g CICS composite sorbent and NICS sorbent were respectively added into $500 \mathrm{~mL}$ of $1.7 \mathrm{mmol} / \mathrm{L}$ cupric sulfate solution with an ionic strength of $0.01 \mathrm{~mol} / \mathrm{L}$ $\mathrm{NaNO}_{3}$ at $\mathrm{pH}$ 5.0. The mixture was shaken at $130 \mathrm{rpm}$. The samples were taken at different time interval and analyzed for the copper concentrations by an inductively coupled plasmaoptical emission spectrometer (ICP-OES) (Perkin-Elmer Optima, 2000, USA).

An intraparticle surface diffusion controlled model illustrated as follows was used to simulate the adsorption history:

$\operatorname{Ds}\left(\frac{\partial^{2} q}{\partial r^{2}}+\frac{2}{r} \frac{\partial q}{\partial r}\right)=\frac{\partial q}{\partial t}, 0 \leq r \leq a_{p}, \quad t>0$

The initial and boundary conditions may be specified as Eqs. (2)-(4).

$\frac{\partial q}{\partial r}=0, r=0$

$D_{\mathrm{s}} \frac{\partial q}{\partial r} \rho_{\mathrm{p}}=k_{f}\left(C-C^{*}\right), r=a_{p}$ $q=0, t=0$

where $C$ and $q$ are the concentrations of the metal ions in bulk $(\mathrm{mmol} / \mathrm{L})$ and in solid phases $(\mathrm{mmol} / \mathrm{g})$, respectively, $\mathrm{C}^{*}$ is the aqueous phase concentration at the particle surface $(\mathrm{mmol} / \mathrm{L})$, in equilibrium with the corresponding concentration in the solid phase $q^{*}(\mathrm{mmol} / \mathrm{g}), D_{\mathrm{s}}$ is the surface diffusivity $\left(\mathrm{m}^{2} / \mathrm{s}\right)$, $\rho_{\mathrm{p}}$ is the particle density $(\mathrm{g} / \mathrm{L})$, and $k_{f}$ is the external masstransfer coefficient $(\mathrm{m} / \mathrm{s})$. Eq. (1) with the initial and the boundary conditions can be numerically solved (Tien, 1994).

In the $\mathrm{pH}$ effect experiment, $50 \mathrm{~mL}$ of $0.262 \mathrm{mmol} / \mathrm{L}$ cupric sulfate solutions with an ionic strength of $0.01 \mathrm{~mol} / \mathrm{L} \mathrm{NaNO}_{3}$ at various initial $\mathrm{pH}$ (2.0-5.5) were prepared in conical flasks. $0.25 \mathrm{~g}$ of CICS was added into the metal solutions. The flasks were shaken at $130 \mathrm{rpm}$ for $24 \mathrm{~h}$. The solution $\mathrm{pH}$ was measured and adjusted accordingly during the experiments by $0.1 \mathrm{~mol} / \mathrm{L} \mathrm{HCl}$ or $0.1 \mathrm{~mol} / \mathrm{L} \mathrm{NaOH}$.

In the sorption isotherm study, $0.1 \mathrm{~g}$ of biosorbent was added into a $50 \mathrm{~mL}$ cupric solution with different initial concentrations $(0.12-2.5 \mathrm{mmol} / \mathrm{L})$. The solution $\mathrm{pH}$ and ionic strength were controlled at 5.0 and $0.01 \mathrm{~mol} / \mathrm{L} \mathrm{NaNO}_{3}$, respectively. Other procedures were the same as those in the above $\mathrm{pH}$ effect experiment.

The copper uptake at equilibrium was calculated by the following equation

$q_{e}=\frac{\mathrm{V}\left(C_{i}-C_{e}\right)}{\mathrm{W}}$

where $q_{e}$ is the equilibrium copper concentration in the sorbent ( $\mathrm{mmol} / \mathrm{g}), \mathrm{V}$ is the solution volume $(\mathrm{L}), \mathrm{W}$ is the amount of sorbent (g), and $C_{i}$ and $C_{e}$ are the initial and equilibrium sorbate concentrations in solution ( $\mathrm{mmol} / \mathrm{L})$, respectively.

The sorption data were fitted by the Langmuir isotherm equation as Eq. (6).

$q_{e}=\frac{q_{\max } b C_{e}}{1+b C_{e}}$

where $q_{e}$ and $C_{e}$ are the same as description in Eq. (5), $q_{\max }$ is the maximum sorption capacity $(\mathrm{mmol} / \mathrm{g}), b$ is the sorption affinity constant related to the binding energy of sorption (L/mmol).

\subsection{Desorption experiments}

The sorption/desorption experiments were conducted to study the potential industrial applications of CICS composite sorbent. EDTA widely used in many studies to remove metal ions from metal loaded absorbent was tested for its suitability for the recovery of sorbent's biosorption capacity.

The experiments were conducted as follows. $400 \mathrm{~mL}$ copper solution with a concentration of $1.28 \mathrm{mmol} / \mathrm{L}$ and $2 \mathrm{~g}$ of CICS composite sorbent was stirred for $24 \mathrm{~h}$ at $\mathrm{pH}$ 5.0. The copper-loaded sorbent was separated from the solution and washed by using DI water. It was subsequently immerged into $20 \mathrm{~mL}$ of $0.1 \mathrm{~mol} / \mathrm{L}$ EDTA mechanically stirred at $200 \mathrm{rpm}$ for $24 \mathrm{~h}$. The copper ion concentrations in the solution were analyzed. The desorbed adsorbents were then treated by $0.1 \mathrm{~mol} / \mathrm{L} \mathrm{NaOH}$ to neutralize hydrogen ions adhered on the adsorbent surface. The regenerated sorbent was used in the subsequent three-cycle sorption/desorption experiments. 


\subsection{Fourier transform infrared spectroscopy}

FTIR spectroscopy was used to probe the surface characteristics of CICS composite sorbent for elucidation of the sorption mechanisms of copper ions. Specimens of various biosorbents were first mixed with $\mathrm{KBr}$ at an approximate ratio of $1 / 100$ (sorbent/KBr) and then ground in an agate mortar. The resulting mixture was pressed at 10 tons for $5 \mathrm{~min}$ to form the pellet, which was characterized using a Nicolet 5700 FTIR spectrometer (Thermo, USA). Thirty-two scans and $2 \mathrm{~cm}^{-1}$ resolution were applied in recording the spectra. The background obtained from scan of pure $\mathrm{KBr}$ was automatically subtracted from the sample spectra. All the spectra were recorded and plotted in the same scale on the absorbance axis.

\subsection{X-ray photoelectron spectroscopy}

The chemical analyses on the virgin and metal loaded CICS composite sorbents were conducted by X-ray photoelectron spectroscopy (Kratos AXIS Ultra, UK). The XPS spectra were obtained by applying the monochromatic $\mathrm{Al} \mathrm{K}_{\alpha} \mathrm{X}$-ray energy source $(1486.7 \mathrm{eV})$ operated at $15 \mathrm{kV}$ and $10 \mathrm{~mA}$. The wide scans were conducted from 0 to $1200 \mathrm{eV}$ with pass energy of $160 \mathrm{eV}$. The high resolution scans were conducted according to the peak being examined with pass energy of $40 \mathrm{eV}$. To compensate for the charging effect, all spectra were calibrated with graphitic carbon as the reference at a binding energy of $284.6 \mathrm{eV}$. The software package Vision (PR2.1.3) and CasaXPS (2.3.12Dev7) were used to fit the XPS spectra peaks.

\section{Results and discussion}

\subsection{Preparation of CICS composite sorbent}

The ratio of chitosan to Sargassum sp. plays an important role during the preparation of CICS composite sorbent. As chitosan is more expensive than Sargassum sp., it is more economical to use more Sargassum sp. in the sorbent preparation. Three mass ratios of chitosan to Sargassum sp. (1:3, 1:4 and 1:5) were used in the preparation. At the mass ratio of $1: 4$ or $1: 5$, the slurry of chitosan and Sargassum sp. was highly thick, resulting to difficulty in the production of granulated sorbents. While the mass ratio was reduced to $1: 3$, the mixture became less viscous. Thus, the ratio was used in the fabrication of sorbent. The CICS composite sorbent has a spherical shape (Fig. I of Supporting Information) with an average diameter of about $1.5 \mathrm{~mm}$.

It has been reported that organic matters can be leached from the marine algae during the sorption operation. Our previous study demonstrated that the organic concentrations of the aqueous solution were 110.9 and $186.3 \mathrm{TOC} \mathrm{mg} / \mathrm{L}$ after contacting with $1 \mathrm{~g} / \mathrm{L}$ Sargassum sp. for $24 \mathrm{~h}$ at controlled $\mathrm{pHs}$ of 5.0 and 2.0, respectively (Chen and Yang, 2005). The organic leaching from our CICS composite sorbent was studied; the sorbent was kept in contact with water for $24 \mathrm{~h}$ at a dosage of $1 \mathrm{~g} /$ L. The TOC values were 14.9 and $22.2 \mathrm{mg} / \mathrm{L}$ at controlled $\mathrm{pHs}$ of 5.0 and 2.0, respectively. The comparison of the organic leaching of raw Sargassum sp. with the CICS composite sorbent clearly indicates that the CICS is more suitable for water treatment.

The concentration of metal (copper ion) used as an imprint ion is another important factor, which would determine the sorption capacity. Table 1 shows that the presence of copper concentration as an imprint ion in the sorbent obviously improves the sorption. The content of imprint ion of $1.28 \mathrm{mg} \mathrm{Cu} / \mathrm{g}$ sorbent is the optimum value to achieve the greatest sorption and thus was selected in the fabrication of the CICS. Under the optimum imprint ion content $(1.28 \mathrm{mg} \mathrm{Cu}$ / g), the sorption capacity of CICS composite sorbent is $0.212 \mathrm{mmol} / \mathrm{g}, 2.3$ times of that of NICS $(0.092 \mathrm{mmol} / \mathrm{g})$ at an initial copper concentration of $0.56 \mathrm{mmol} / \mathrm{L}$.

The measurement of specific surface area of sorbents was conducted. It was found that CICS and NICS had specific surface area of $11.6 \mathrm{~m}^{2} / \mathrm{g}$ and $7.3 \mathrm{~m}^{2} / \mathrm{g}$, respectively. The ionimprint operation has some improvement (enlargement) in the specific surface area, which is essentially beneficial to the adsorption kinetics and capacity.

\subsection{Sorption kinetics}

Fig. 2 shows the kinetics of copper biosorption onto CICS and NICS. About $85 \%$ of total (ultimate) copper sorption on CICS and NICS rapidly occurs within $2 \mathrm{~h}$, followed by a relatively slow process. The sorption equilibrium can be achieved within about $6 \mathrm{~h}$. Comparison of this finding with those reported in literature shows that the immobilization does not obviously alter the biosorption kinetics (Kratochvil and Volesky, 1998; Chen and Yang, 2005).

As the specific surface area of sorbents is relatively low, it can be assumed that the surface diffusion controls the

Table 1 - Effect of the imprinted $\mathrm{Cu}^{2+}$ concentration in preparation on sorption capacity of CICS.

\begin{tabular}{|c|c|c|c|c|}
\hline \multirow[t]{3}{*}{$\mathrm{C}_{\mathrm{o}} \stackrel{2+}{\mathrm{Cu}}(\mathrm{mmol} / \mathrm{L})^{\mathrm{a}}$} & \multirow[t]{3}{*}{$\begin{array}{l}\text { Sorption capacity } \\
\text { of NICS, } q(\mathrm{mmol} / \mathrm{g})\end{array}$} & \multicolumn{3}{|c|}{$\begin{array}{l}\text { Sorption capacity of CICS with different imprinted } \\
\qquad \mathrm{Cu}^{2+} \text { concentration, } q(\mathrm{mmol} / \mathrm{g})\end{array}$} \\
\hline & & \multicolumn{3}{|c|}{$\mathrm{C}_{\mathrm{I}}{ }_{\mathrm{Cu}}^{2+}(\mathrm{mg} / \mathrm{g} \text { sorbent })^{\mathrm{b}}$} \\
\hline & & 0.67 & 1.28 & 2.64 \\
\hline 0.56 & 0.092 & 0.145 & 0.212 & 0.148 \\
\hline 1.00 & 0.152 & 0.278 & 0.341 & 0.273 \\
\hline 3.00 & 0.325 & 0.593 & 0.749 & 0.582 \\
\hline
\end{tabular}

a $\mathrm{C}_{\mathrm{o} \mathrm{Cu}}{ }^{2+}$ : the initial $\mathrm{Cu}^{2+}$ concentration in the solution $(\mathrm{mmol} / \mathrm{L})$.

${ }^{b ~} \mathrm{C}_{\mathrm{I} \mathrm{Cu}}{ }^{2+}$ : the imprinting $\mathrm{Cu}^{2+}$ concentration in the preparation (mg/g sorbent). 


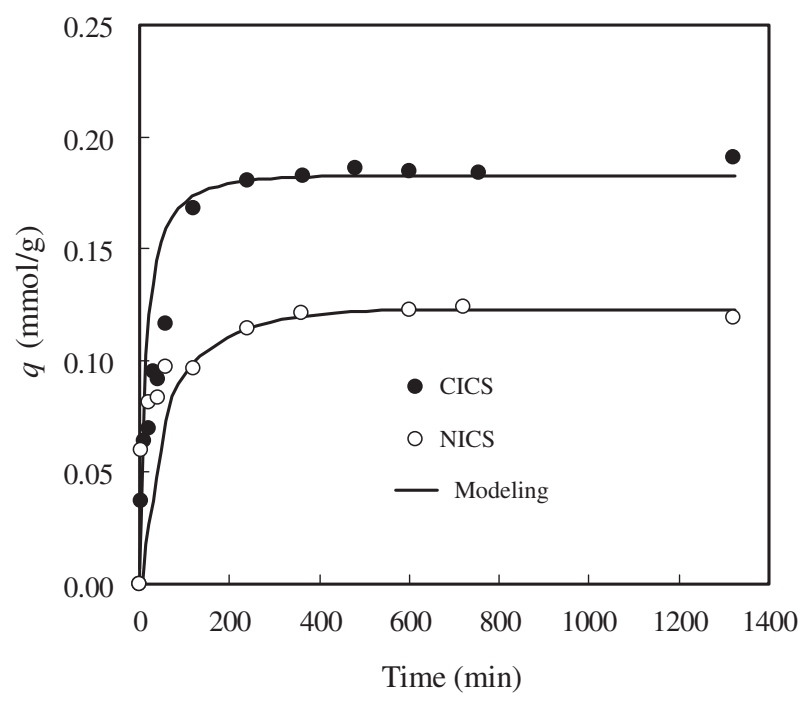

Fig. 2 - Kinetics of copper biosorption by CICS and NICS. $\left(m=4 \mathrm{~g} / \mathrm{L} ; \mathrm{pH}=5.0 ;\left[\mathrm{Cu}^{2+}\right]_{0}=1.17 \mathrm{mmol} / \mathrm{L}\right.$; $\left.\left[\mathrm{NaNO}_{3}\right]=0.01 \mathrm{~mol} / \mathrm{L}\right)$.

biosorption kinetics. The intraparticle surface diffusion controlled model was used in the simulation of adsorption history. As shown in Fig. 2, the model well describes the data of biosorption kinetics. Since the size of sorbents and stirring speed are the same in the experiments, the $k_{f}$ values of CICS and NICS are $6.4 \times 10^{-5} \mathrm{~m} / \mathrm{s}$. The diffusivities of CICS and NICS are $1.0 \times 10^{-11}$ and $9 \times 10^{-12} \mathrm{~m}^{2} / \mathrm{s}$, respectively. We previously reported that the $k_{f}$ and $D_{\mathrm{s}}$ of Sargassum sp. were $1.3 \times 10^{-4} \mathrm{~m} / \mathrm{s}$ and $3.7 \times 10^{-12} \mathrm{~m}^{2} / \mathrm{s}$, respectively (Chen and Yang, 2005). The diffusivity of CICS is slightly higher than that of Sargassum sp., possibly due to the presence of chitosan used for the immobilization of Sargassum sp.. The external mass-transfer coefficient is lower than that of Sargassum sp. which likely results from the larger size and lower porosity of our sorbent.

\subsection{Effect of $\mathrm{pH}$ on copper sorption}

The distribution of metal species in aqueous solution as a function of $\mathrm{pH}$ reveals that copper (maximum concentration: $2.0 \mathrm{mmol} / \mathrm{L}$ ) ions precipitate in the forms of metal oxides or hydroxides at $\mathrm{pH}>6$ (Chen et al., 2003; Chen and Yang, 2005). Hence, the pH effect experiments were conducted at $\mathrm{pH}$ between 2 and 5.5, so sorption, not precipitation was responsible for the removal of copper.

As shown in Fig. 3, the metal uptake increases with the increasing equilibrium solution $\mathrm{pH}$ and reaches a plateau at $\mathrm{pH}>4.7$, which is consistent with what was observed in the sorption of metals by biosorbents, such as prontonated brown alga Sargassum (Fourest and Volesky, 1996; Chen and Wang, 2001; Chen and Yang, 2006; Yang and Chen, 2008). At $2<\mathrm{pH}<4$, the amine groups on the surface of the sorbent could be easily protonated, which induces an electrostatic repulsion of copper ion. Competition between protons and $\mathrm{Cu}$ ions for sorption sites greatly decreases the sorption capacity (Chen and Wang, 2001; Lim et al., 2008). As pH is increased, the functional groups become more available for

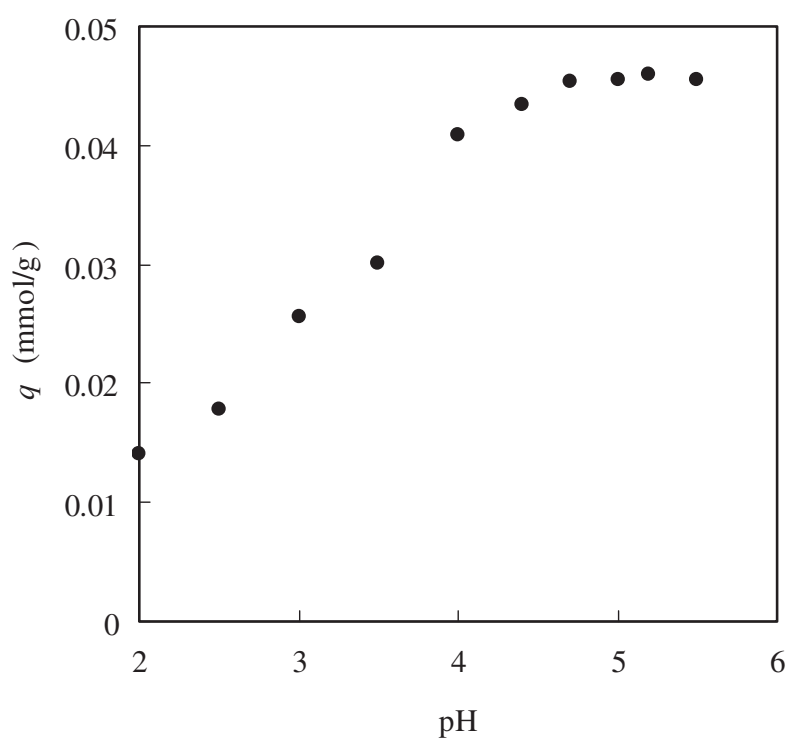

Fig. 3 - pH effect on copper uptake by CICS. $(m=5.0 \mathrm{~g} / \mathrm{L}$; $\left.\left[\mathrm{Cu}^{2+}\right]_{0}=0.262 \mathrm{mmol} / \mathrm{L} ;\left[\mathrm{NaNO}_{3}\right]=0.01 \mathrm{~mol} / \mathrm{L}\right)$.

metal ion binding, and hence the biosorption is enhanced. As the optimum $\mathrm{pH}$ for copper sorption on CICS was above 4.7, the $\mathrm{pH}$ of 5.0 was set in the subsequent sorption isotherm experiments.

\subsection{Sorption isotherms}

The sorption isotherms of copper on CICS, NICS, CLC and Sargassum sp. are presented in Fig. 4. The amounts of copper adsorbed (q) increase with an increase equilibrium copper concentration in solution $\left(C_{e}\right)$.

The sorption data were fitted by the Langmuir equation and the calculated parameters are summarized in Table 2 . It is shown that the Langmuir equation can well describe the

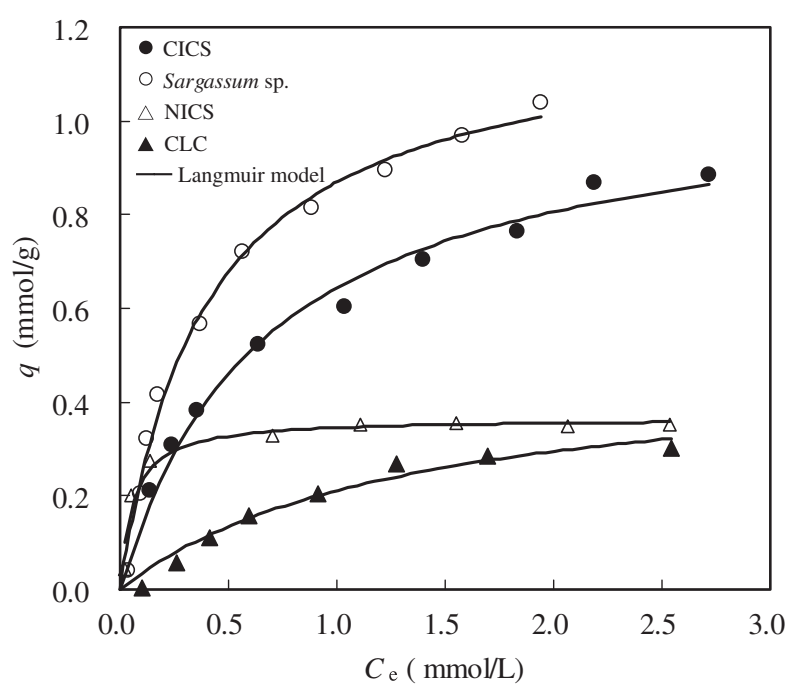

Fig. 4 - Copper biosorption isotherms of different adsorbents (CICS, NICS, CLC and Sargassum sp.) $(m=2.0 \mathrm{~g} / \mathrm{L}$; $\left.\mathrm{pH}=5.0 ;\left[\mathrm{NaNO}_{3}\right]=0.01 \mathrm{~mol} / \mathrm{L}\right)$. 
Table 2 - Langmuir constants for copper sorption by different sorbents.

\begin{tabular}{lccc} 
& $q_{\max }(\mathrm{mmol} / \mathrm{g})$ & $b(\mathrm{~L} / \mathrm{mmol})$ & $r^{2}$ \\
\hline CICS & 1.08 & 1.49 & 0.98 \\
NICS & 0.49 & 0.76 & 0.97 \\
CLC & 0.36 & 17.2 & 0.95 \\
Sargassum sp. powder & 1.21 & 2.53 & 0.99 \\
\hline
\end{tabular}

sorption isothermal behaviors with high correlation coefficients $\left(r^{2}=0.95-0.99\right)$. The maximum copper sorption capacities $\left(q_{\max }\right)$ of CICS, NICS, CLC, and Sargassum sp. are 1.08, 0.49, 0.36 and $1.21 \mathrm{mmol} / \mathrm{g}$, respectively. The copper uptake is only reduced by $10 \%$ due to our ion-imprint immobilization of the raw biomass (CICS vs. Sargassum sp.). However, it increases by $120 \%$ due to the inclusion of raw biomass (CICS vs. NICS). As both CICS and NICS sorbents have chitosan and Sargassium sp., it can be concluded that more sorption sites become available on the CICS than the NICS as a result of ion-imprint modification.

It was reported that the sorption capacities of copper on the granular activated carbon (Chen et al., 2003), the algal biomass (Aksu et al., 1992; Davis et al., 2003; Ozer et al., 2004), and the poly (vinyl alcohol) immobilized Sargassum (Sheng et al., 2008), and the calcium alginate-entrapped algae sorbent (Mehta and Gaur, 2001) were 0.2, 0.25-1.14, 0.21 and $0.7 \mathrm{mmol} / \mathrm{g}$, respectively. It is clearly indicated that the ionimprinted composite sorbent developed in this study has a great potential for the treatment of heavy metal wastewater from various industries.

\subsection{Desorption study}

$0.1 \mathrm{~mol} / \mathrm{L}$ EDTA ( pH 4.5) was used as elusion agents for the desorption of copper ions adsorbed onto the CICS composite sorbent. 95\% of desorption efficiency was achieved within $6 \mathrm{~h}$. As the copper ions can strongly be chelated with the functional groups of EDTA, they can be easily released into the aqueous solution from the sorbent. After copper ions are desorbed, more hydrogen ions of EDTA become available and therefore adhered onto the surface of the sorbent. Such important functional groups on sorbent as $-\mathrm{NH}_{2}$ and $-\mathrm{COO}^{-}$ are protonated to $-\mathrm{NH}_{3}^{+}$and $-\mathrm{COOH}$, leading to less metal binding on the sorbent (Su et al., 2003). As a result, $0.1 \mathrm{~mol} / \mathrm{L}$ $\mathrm{NaOH}$ was used to neutralize hydrogen ions in the regeneration.

The amount of copper ions adsorbed and the desorption efficiency in three consecutive sorption-desorption cycles using EDTA are presented in Table 3. The desorption efficiency

Table 3 - Sorption and desorption behaviors of copper ions on $\mathbf{C u}$ (II)-CTSS.

Uptake (mmol/g)

Desorption efficiency (\%)

\begin{tabular}{lll}
\hline Cycle I & 0.45 & $97.2 \%$ \\
Cycle II & 0.43 & $98.3 \%$ \\
Cycle III & 0.43 & $96.8 \%$ \\
\hline
\end{tabular}

is as high as $96.8-98.3 \%$. Most importantly, the sorption capacity is almost unaffected by the number of cycles, implying the higher possibility of the recovery of the copper ions and the reuse of the sorbent in industrial-scale applications. More studies are being conducted in our laboratory to further improve the sorbent in order that it will eventually behave like an ion exchange resin and can be used for many cycles (Chen et al., 2002).

\subsection{Sorption mechanism of CICS}

FTIR and XPS analyses were used to investigate the adsorption mechanisms of the CICS composite sorbent. Fig. 5 shows the FTIR spectra of Sargassum sp., CLC, NICS, CICS, copper-loaded CICS, and CICS with one cycle of sorption-desorption. The broad and strong band ranging from 3200 to $3600 \mathrm{~cm}^{-1}$ may be due to the overlapping of $-\mathrm{OH}$ and $-\mathrm{NH}$ stretching bands. The peak at wavenumber of $1539.5 \mathrm{~cm}^{-1}$ in CLC, $1535.0 \mathrm{~cm}^{-1}$ in NICS and $1538.4 \mathrm{~cm}^{-1}$ in CICS can be assigned to the presence of $-\mathrm{NH}_{2}$ group (Clothup et al., 1990). The absorbance at above two wavenumbers in the CICS is much stronger than the CLC and NICS; this indicates that the modification by the ionimprint in the CICS preparation could preserve the more sorption sites for copper ions uptake. The absorbance at wavenumber of $1640.0 \mathrm{~cm}^{-1}$ and $1421.5 \mathrm{~cm}^{-1}$ in Sargassum sp. corresponds to stretching vibrations of carbonyl double bond $\left(v_{\mathrm{C}=\mathrm{O}}\right)$ and carbon-oxygen single bond $\left(v_{\mathrm{C}-\mathrm{O}}\right)$, respectively (Clothup et al., 1990). The strong absorbance at $1645.4 \mathrm{~cm}^{-1}$ and $1410.3 \mathrm{~cm}^{-1}$ in CICS should be contributed by the functional groups from Sargassum sp.

The vibration intensity of the $-\mathrm{NH}_{2}$ bonds at $1538.4 \mathrm{~cm}^{-1}$ and the $\mathrm{C}-\mathrm{N}$ stretching vibration at $1325.4 \mathrm{~cm}^{-1}$ are reduced significantly after the copper sorption onto the CICS (Curve (e))

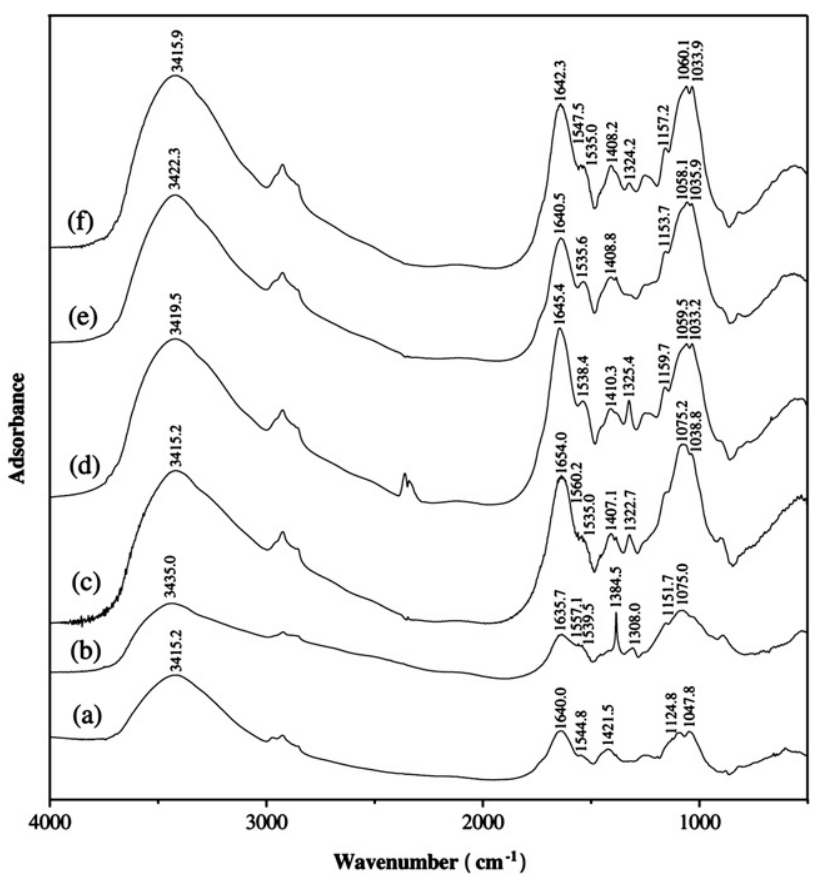

Fig. 5 - FTIR spectra (a) Sargassum sp.; (b) CLC; (c) NICS; (d) CICS; (e) Copper-loaded CICS; and (f) CICS with one cycle of $\mathrm{Cu}^{2+}$ sorption-desorption. 
and are recovered after the desorption (Curve (f)). These amino groups are involved in the copper sorption; the desorption by EDTA could restore the sorption ability of amino groups. After the copper ions are adsorbed onto the CICS, the carbonyl double bond stretching band exhibits a clear shift to a lower frequency at $1640.5 \mathrm{~cm}^{-1}$, while the carbon-oxygen single bond band shifts to $1408.8 \mathrm{~cm}^{-1}$, corresponding to the complexation of copper to $\mathrm{C}=\mathrm{O}$ and $\mathrm{C}-\mathrm{O}$ bonds. This indicates the typical carboxylic absorption. The differences of frequencies of $\mathrm{C}=\mathrm{O}$ and $\mathrm{C}-\mathrm{O}$ bond stretching $\left(\Delta=v_{\mathrm{C}=\mathrm{O}}-v_{\mathrm{C}-\mathrm{O}}\right)$ in Sargassum sp., CICS, copper-loaded CICS and CICS suffered one sorption-desorption cycle are 228.5, 235.1, 231.7 and 234.7, respectively. The difference between $\mathrm{C}=\mathrm{O}$ and $\mathrm{C}-\mathrm{O}$ bond stretching is related to the relative symmetry of these two carbon-oxygen bonds and reflects the nature of carboxyl group binding status. The CICS has larger $\Delta$ value $\left(235.1 \mathrm{~cm}^{-1}\right)$ than the metal loaded CICS $\left(231.7 \mathrm{~cm}^{-1}\right)$. The change in $\Delta$ in the presence of copper ions clearly indicates more involvement of carboxyl groups forming complexes with copper ions (Chen and Yang, 2006). Another change to be noted in Fig. 5 is that the intensity of the peak representing the $-\mathrm{COO}^{-}$groups after copper sorption becomes much lower than that for the $-\mathrm{COO}^{-}$groups before the sorption (comparing the peak at 1645.4-1640.5 cm $\mathrm{cm}^{-1}$ in Curves (d) and (e) of Fig. 5, respectively). The results indicate that $-\mathrm{COO}^{-}$groups are involved in the metal binding. Chen and Yang (2006) reported that the carboxyl groups of Sargassum sp. were the active functional groups for copper ion uptake and that the copper sorption on Sargassum sp. was mainly through the formation of $\mathrm{Cu}^{2+}-\mathrm{COO}^{-}$complex. These further confirm that both chitosan and Sargassum sp. are involved in the cupric sorption.

The XPS studies of virgin and copper-loaded of CLC and CICS were conducted. The results of wide scan of samples given in Fig. II of Supporting Information clearly show a small peak around binding energy (BE) of $933 \mathrm{eV}$ after the copper biosorption on both NICS and CICS, indicating the accumulation of copper on the sorbents.

The high resolution XPS spectra of $\mathrm{N}$ 1s are shown in Fig. 6. The deconvoluted $\mathrm{N}$ 1s spectrum of CICS shown in Fig. 6c comprises two peaks with BEs of 399.73 and $401.64 \mathrm{eV}$. The peak at $399.73 \mathrm{eV}$ is attributed to the $\mathrm{N}$ atom in the $\mathrm{R}-\mathrm{NH}_{2}$ group. The peak at $401.64 \mathrm{eV}$ is assigned to a high oxidation states of nitrogen with positive charges $\left(\mathrm{R}-\mathrm{NH}_{3}^{+}\right)$(Jin and Bai, 2002; Liu and Bai, 2006). The similar N 1s spectrum of CICS as that of NICS confirms that the ion-imprinting process dose not influence the states of $\mathrm{N}$ atom. After the copper sorption, the BEs of the two peaks of N 1s shift to 400.15 and $402.14 \mathrm{eV}$, respectively. This is likely due to the formation of $\mathrm{R}-\mathrm{NH}_{2} \mathrm{Cu}^{2+}$ complexes as shown in Eqs (7) and (8). A lone pair of electrons in the nitrogen atom is donated to the covalent bond between $\mathrm{N}$ and $\mathrm{Cu}^{2+}$. As a consequence, the electron cloud density of the nitrogen atom is reduced, resulting in a higher BE peak observed.

$\mathrm{R}-\mathrm{NH}_{2}+\mathrm{Cu}^{2+} \rightarrow \mathrm{R}-\mathrm{NH}_{2} \mathrm{Cu}^{2+}$

$\mathrm{R}-\mathrm{NH}_{3}^{+}+\mathrm{Cu}^{2+} \rightarrow \mathrm{R}-\mathrm{NH}_{2} \mathrm{Cu}^{2+}+\mathrm{H}^{+}$

The deconvolution of C 1s spectra of CICS in Fig. 7c produces four peaks with BE of 284.80, 286.41, 287.83 and $288.92 \mathrm{eV}$ respectively. These peaks can be assigned to the $\mathrm{C}$ atom in forms of $\mathrm{C}-\mathrm{C}, \mathrm{C}-\mathrm{O}, \mathrm{O}-\mathrm{C}-\mathrm{O}$ and $\mathrm{O}-\mathrm{C}=\mathrm{O}$, and the last three can be assigned to alcoholic, ether and carboxylate groups (Moulder et al., 1992; Lim et al., 2008). The carbon atoms in these three respective organic functional groups of the CICS are typical in algae polysaccharides and have different electron densities (Chen and Yang, 2006). After the copper binding onto the CICS, the binding energy of $\mathrm{C}-\mathrm{O}$, $\mathrm{O}-\mathrm{C}-\mathrm{O}$ and $\mathrm{O}=\mathrm{C}-\mathrm{O}$ shifts to $286.57,288.14$ and $289.41 \mathrm{eV}$,
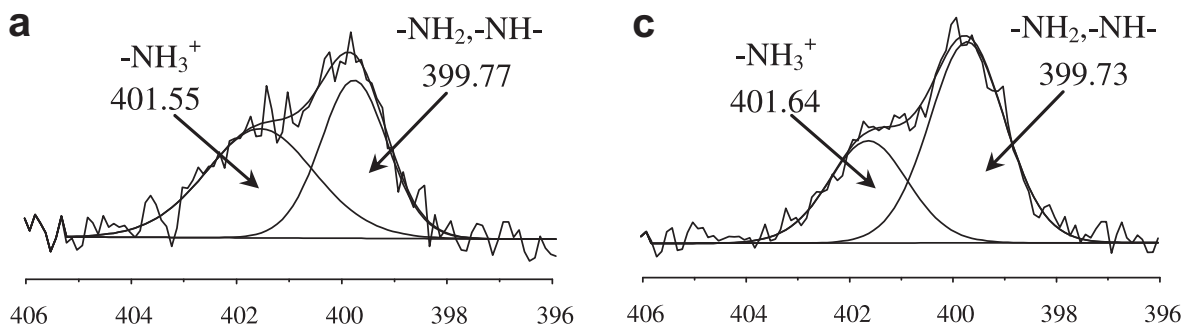

b $-\mathrm{NH}_{2},-\mathrm{NH}-$

d

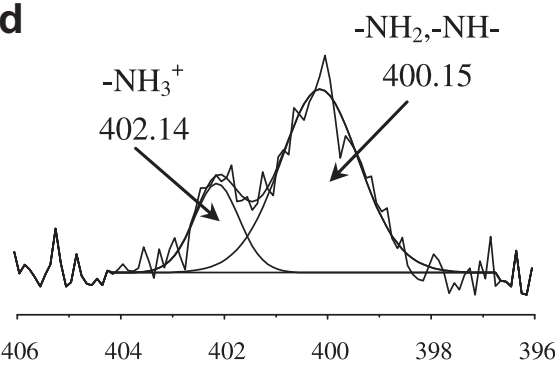

Binding Energy (eV)

Binding Energy (eV)

Fig. 6 - XPS N 1s spectra of adsorbent. (a) NICS; (b) Copper-loaded NICS; (c) CICS and (d) Copper-loaded CICS. 

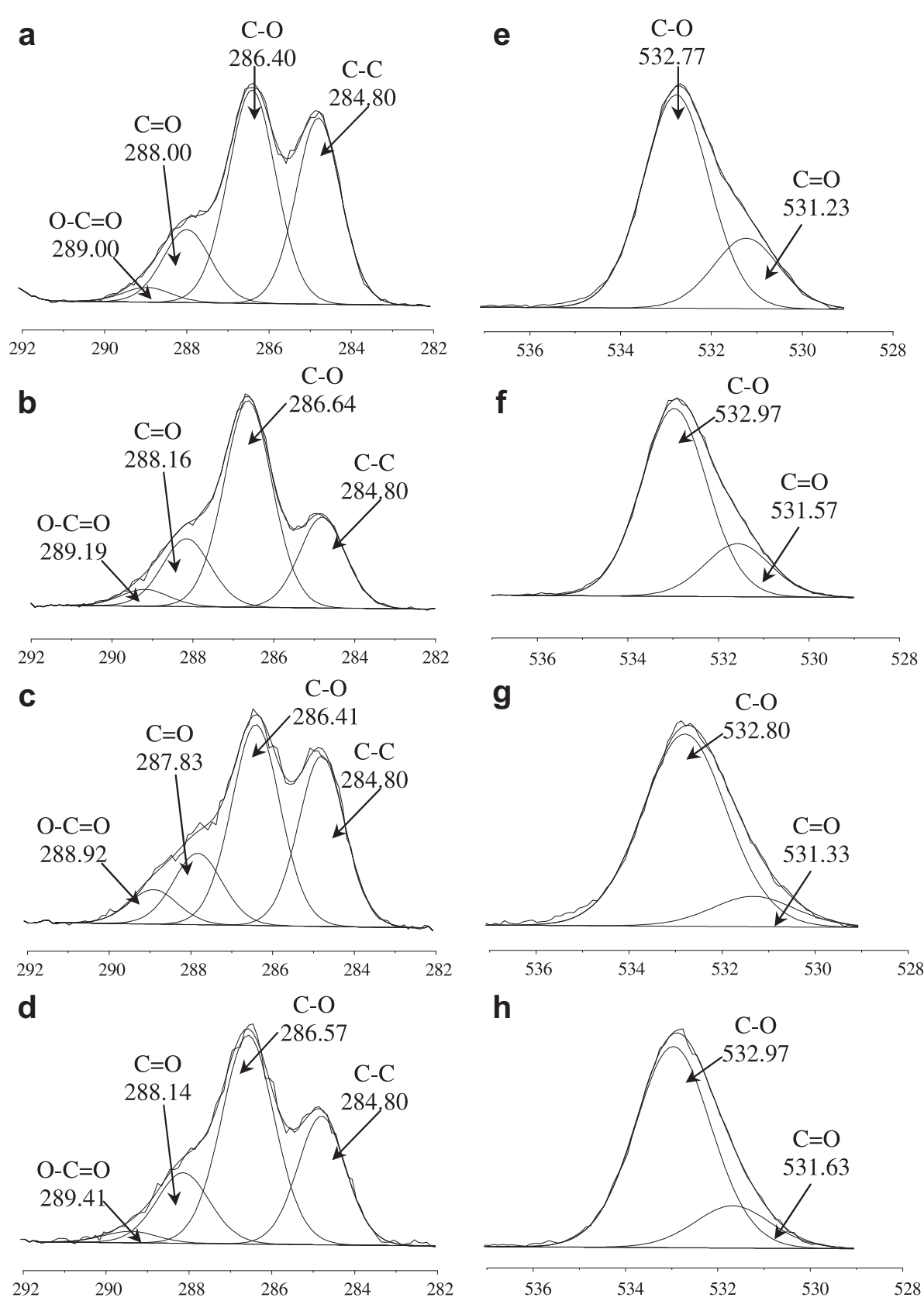

Binding energy, eV

C1s

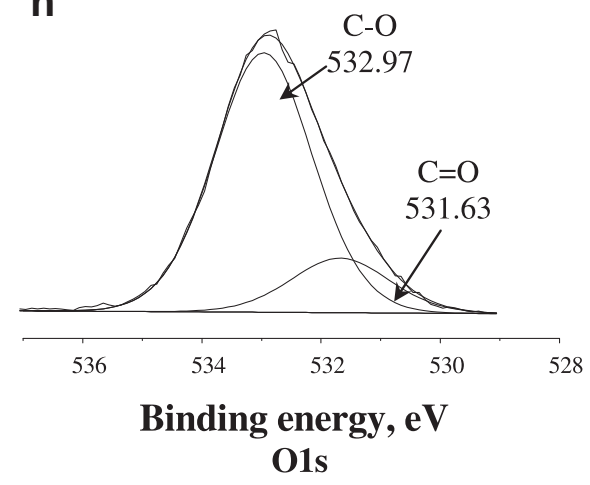

Fig. 7 - XPS spectra of adsorbent. (a) C 1s of NICS; (b) C 1s of Copper-loaded NICS; (c) C 1s of CICS and (d) C 1s of Copperloaded CICS; (e) $O$ 1s of NICS; (f) $O 1 \mathrm{~s}$ of Copper-loaded NICS; (g) $O$ 1s of CICS and (h) $O$ 1s of Copper-loaded CICS.

respectively. It indicates that alcoholic, ether and carboxylate groups in the CICS become involved in the cupric ion sorption, in which oxygen atom donates electrons to cupric ions and thus the electron density at the adjacent carbon atom in $\mathrm{C}=\mathrm{O}$ and $\mathrm{C}-\mathrm{O}$ decreases. The similar results can be found for the cases of NICS and copper-loaded NICS; this indicates that the sorption mechanism of CICS is the same as that of NICS.

Furthermore, the $\mathrm{O}$ 1s spectra can be deconvoluted into two individual component peaks, which come from the different functional groups and overlap on each other, as shown in Fig. 7e-h. The peaks at binding energy of $531.33 \mathrm{eV}$ and $532.80 \mathrm{eV}$ (for CICS) can be assigned to the oxygen atom in the forms of $\mathrm{C}=\mathrm{O}$ (carboxyl and or quinine groups) and $-\mathrm{OH}$ or $\mathrm{C}-\mathrm{O}$ groups, respectively. Fig. $7 \mathrm{e}-\mathrm{h}$ shows that the binding energy of the peaks of the copper-loaded sorbent has a certain degree of shift, which is due to the copper ions bound onto the oxygen atoms and thus the electron density towards the oxygen atoms is decreased (Moulder et al., 1992). The changes in the $\mathrm{BE}$ of $\mathrm{C}-\mathrm{O}$ and $\mathrm{C}=\mathrm{O}$ indicate that both are involved in the sorption of copper, which are consonant with the FTIR analysis and the observations in C 1 s analysis. 


\section{Conclusion}

A novel ion-imprinted chitosan/Sargassum sp. complex sorbent for effective copper ions removal is developed in this study. Three main steps are used in the fabrication of sorbent as illustrated in Fig. 1: First, the epichlorohydrin as a cross-linker is added to the mixture of copper, acetic acid and chitosan. Second, Sargassum sp. is added into the cross-linked mixture, which is then dropwise injected into a sodium pyrophosphate and potassium oxalate solution to form small pellet-typed sorbent. Third, the particle is eluded by EDTA and $\mathrm{NaOH}$, forming the sorbent for improved sorption of heavy metal ions.

The copper sorption on CICS is highly pH-dependent; it increases as the solution $\mathrm{pH}$ is increased. The maximum uptake capacity is achieved at $\mathrm{pH}$ 4.7-5.5. The sorbent has strong affinity towards copper ions with a maximal sorption capacity of $1.08 \mathrm{mmol} / \mathrm{g}$. Lower organic leaching is found during the sorption. The adsorbed copper ions can be desorbed and the sorption capacity is almost not affected by the desorption process. The high efficiency, low organic leaching and reuseability of CICS make it a promising sorbent for the treatment of heavy metals from aqueous solutions.

The FTIR and XPS studies show that the ion-imprinting method in sorbent preparation can shield the amine groups in chitosan in cross-linking process and enhance the sorption capacity. In addition, the carboxyl functional groups on Sargassum sp. play an important role in metal binding; this shows that Sargassum sp. contributes to the sorption capacity. An intraparticle surface diffusion controlled model is used to simulate the adsorption kinetics data. It is demonstrated that the model well describes the sorption history of the CICS and NICS.

\section{Acknowledgements}

This work was supported by National Natural Science Foundation of China (Grant No. 50728806). The fellowship to YM Zheng funded by Agency for Science, Technology and Research, Singapore is appreciated (Grant No. 092101 0059).

\section{Appendix. Supporting Information}

Supporting information of this article can be founded in online version at doi:10.1016/j.watres.2010.08.017.

\section{R E F E R E N C E S}

Aksu, Z., Sag, Y., Kutsal, T., 1992. The biosorption of Copper(II) by C. vulgaris and Z. ramigera. Environ. Technol. 13, 579-586.

Bassi, R., Prasher, S.O., Simpson, B.K., 2000. Removal of selected metal ions from aqueous solutions using chitosan flakes. Sep. Sci. Technol. 35, 547-560.

Bayramoğlu, G., Yakup Arıca, M., 2009. Construction a hybrid biosorbent using Scenedesmus quadricauda and Ca-alginate for biosorption of $\mathrm{Cu}(\mathrm{II}), \mathrm{Zn}$ (II) and $\mathrm{Ni}(\mathrm{II})$ : kinetics and equilibrium studies. Bioresour. Technol. 100, 186-193.
Chen, J.P., Chua, M.L., Zhang, B.P., 2002. Effects of competitive ions, humic acid, and $\mathrm{pH}$ on removal of ammonium and phosphorous from the synthetic industrial effluent by ion exchange resins. Waste Manag. 22, 711-719.

Chen, J.P., Wang, L., 2001. Characterization of a Ca-alginate based ion-exchange resin and its applications in lead, copper, and zinc removal. Sep. Purif. Technol. 36, 3617-3637.

Chen, J.P., Yang, L., 2005. Chemical modification Sargassum sp. for prevention of organic leaching and enhancement of uptake during metal biosorption. Ind. Eng. Chem. Res. 44, 9931-9942.

Chen, J.P., Yang, L., 2006. Study of a heavy metal biosorption onto raw and chemically modified Sargassum sp. via spectroscopic and modeling analysis. Langmuir 22, 8906-8914.

Chen, J.P., Yoon, J.T., Yiacoumi, S., 2003. Effects of chemical and physical properties of influent on copper sorption onto activated carbon fixed-bed columns. Carbon 41, 1635-1644.

Clothup, N.B., Daly, L.H., Wiberley, S.E., 1990. Introduction to Infrared and Raman Spectroscopy, third ed. Academic Press, London.

Davis, T.A., Volesky, B., Mucci, A.A., 2003. Review of the biotechnology of heavy metal biosorption by brown algae. Water Res. 37, 4311-4330.

Fourest, E., Volesky, B., 1996. Contribution of sulphonate groups and alginate to heavy metal biosorption by the dry biomass of Sargassum fluitans. Environ. Sci. Technol. 30, 277-282.

Guibal, E., 2004. Interactions of metal ions with chitosan-based sorbents; a review. Sep. Purif. Technol. 38, 43-74.

Hsien, T.Y., Rorrer, G.L., 1997. Heterogeneous cross-Linking of chitosan gel beads: kinetics, modeling, and influence on cadmium ion adsorption capacity. Ind. Eng. Chem. Res. 36 (9), 3631-3638.

Jin, L., Bai, R.B., 2002. Mechanisms of lead adsorption on chitosan/ PVA hydrogel beads. Langmuir 18, 9765-9770.

Kratochvil, D., Volesky, B., 1998. Biosorption of Cu from ferruginous wastewater by algal biomass. Water Res. 32, 2760-2768.

Lim, S.F., Zheng, Y.M., Zou, S.W., Chen, J.P., 2008. Characterization of copper adsorption onto an alginate encapsulated magnetic sorbent by a combined FTIR, XPS and mathematical modeling study. Environ. Sci. Technol. 42, 2551-2556.

Liu, C.X., Bai, R.B., 2006. Adsorptive removal of copper ions with highly porous chitosan/cellulose acetate blend hollow fiber membranes. J. Memb. Sci. 284, 313-322.

Mata, Y.N., Blázquez, M.L., Ballester, A., González, F., Muñoz, J.A., 2009. Biosorption of cadmium, lead and copper with calcium alginate xerogels and immobilized Fucus vesiculosus. J. Hazard. Mater. 163, 555-562.

Mehta, S.K., Gaur, J.P., 2001. Removal of Ni and Cu from single and binary metal solutions by free and immobilized Chlorella vulgaris. Eur. J. Protistol. 37, 261-271.

Mehta, S.K., Gaur, J.P., 2005. Use of algae for removing heavy metal ions from wastewater: progress and prospects. Crit. Rev. Biotechnol. 25, 113-152.

Moulder, J.F., Stickle, W.F., Sobol, P.E., Bomben, K.D., 1992. Handbook of X-ray Photoelectron Spectroscopy: a Reference Book of Standard Spectra for Identification and Interpretation of XPS Data; Perkin-Elmer Corp. Physical Electronics Division, Eden Prairie, MN.

Ozer, A., Ozer, D., Ekiz, H.I., 2004. The equilibrium and kinetic modeling of the biosorption of Copper(II) ions on Cladophora crispata. Adsorption 10, 317-326.

Rangsayatorn, N., Pokethitiyook, P., Upatham, E.S., Lanza, G.R., 2004. Cadmium biosorption by cells of Spirulina platensis TISTR 8217 immobilized in alginate and silica gel. Environ. Int. 30, 57-63.

Ruiz, M., Sastre, A.M., Guibal, E., 2000. Palladium sorption on glutaraldehyde-crosslinked chitosan. React. Funct. Polym. 45, 155-173. 
Sheng, P.X., Wee, K.H., Ting, Y.P., Chen, J.P., 2008. Biosorption of copper by immobilized marine algal biomass. Chem. Eng. J. 136, 156-163.

Su, H.J., Wang, Z.X., Tan, T.W., 2003. Adsorption of $\mathrm{Ni}^{2+}$ on the surface of molecularly imprinted adsorbent from Penicillium chysogenum mycelium. Biotechnol. Lett. 25, 949-953.

Tien, C., 1994. Adsorption Calculations and Modeling. Butterworth-Heinemann, Boston, MA.
Volesky, B., 2007. Biosorption and me. Water Res. 41, 4017-4029.

Wang, J.L., Chen, C., 2009. Biosorbents for heavy metals removal and their future. Biotechnol. Adv. 27, 195-226.

Yang, L., Chen, J.P., 2008. Biosorption of hexavalent chromium onto raw and chemically modified Sargassum sp. Bioresour. Technol. 99, 297-307.

Zhao, F., Yu, B.Y., Yue, Z.R., Wang, T., Wen, X., Liu, Z.B., Zhao, C.S., 2007. Preparation of porous chitosan gel beads for Copper(II) ion adsorption. J. Hazard. Mater. 147, 67-73. 